\title{
INTERAÇÕES ENTRE PLUVIOSIDADE E A INTENSIFICAÇÃO DE PROCESSOS GEOMORFOLÓGICOS EM BACIAS HIDROGRÁFICAS URBANAS: UM ESTUDO APLICADO NAS BACIAS DO RIO GRANDE E RIO ANIL NO MUNICÍPIO DO RIO DE JANEIRO
}

\author{
INTERACTIONS BETWEEN RAINFALL AND INTENSIFICATION OF GEOMORPHOLOGICAL PROCESSES IN URBAN RIVER \\ BASINS: A STUDY APPLIED IN THE RIO GRANDE AND RIO ANIL URBAN BASINS, IN THE RIO DE JANEIRO CITY
}

\section{RESUMO}

Nas áreas urbanas, eventos pluviais extremos podem desencadear processos erosivos e hidrológicos catastróficos quando associados a formas de uso e ocupação desordenadas. Com o intuito de corroborar essa afirmativa, este trabalho teve como objetivo analisar as condições pluviométricas e o histórico de eventos extremos que causaram movimentos de massa e inundações nas bacias urbanas do Rio Grande e Rio Anil, no município do Rio de Janeiro. Os resultados demostraram que a seletividade espacial das políticas de planejamento urbano aliada a alta pluviosidade regional tem intensificado a magnitude e os efeitos dos fenômenos de superfície nas bacias estudadas, aumentando os riscos de desastres as populações vulneráveis.

Palavras-chave: Eventos pluviais extremos, bacias hidrográficas urbanas, movimentos de massa, enchentes e inundações.

\begin{abstract}
In urban areas, extreme rainfall events can trigger catastrophic erosion and hydrological processes when associated with disordered forms of land use and land change. In order to prove this, the objective of this study was to analyze the pluviometric conditions and the history of extreme events that caused mass movements end floods; in the Rio Grande and Rio Anil urban river basins, in the Rio de Janeiro city. The results showed that the spatial selectivity of urban planning policies combined with high regional rainfall has intensified the magnitude and effects of surface phenomena in the studied basins, increasing the risks to the vulnerable population.
\end{abstract}

Keywords: Extreme rainfall events, urban river basins, mass movements and floods.
Regina Paula Benedetto de Carvalho ${ }^{\text {a }}$

(i) Cássia Barreto Brandão ${ }^{b}$

${ }^{a}$ Universidade Federal de Minas Gerais (UFMG), Belo Horizonte, MG, Brasil

${ }^{\text {b }}$ Universidade do Estado do Rio de Janeiro (UERJ), Rio de Janeiro, RJ, Brasil

DOI: 10.12957/geouerj.2020.35486

Correpondência:

reginapaulabenedettodec@gmail.com

Recebido em: 28 jun. 2018

Revisado em: 3 ago. 2020

Aceito em: 6 out.2020 


\section{INTRODUÇÃO}

As características climáticas de um ambiente têm influência direta na formação e capacidade de transferência dos fluxos de água e materiais de um sistema ambiental. Estas condicionam a distribuição e quantidade de água que precipita nos sistemas e, em função das características do relevo, dos solos e da cobertura e uso da terra, podem desencadear processos geomorfológicos de diferentes intensidades (HARVEY, 2002; FRYIRS, 2013).

Em áreas urbanas localizadas em ambientes de alta pluviosidade, o aumento da intensidade dos fluxos durante os meses chuvosos tende a causar processos erosivos e hidrológicos catastróficos devido ao encadeamento de processos naturais associados a ocupação irregular de áreas de encosta e vales fluviais, o que gera o aumento dos riscos de movimentos de massa e inundações durante esse período (RIBEIRO et al., 2014).

O presente trabalho apresenta um estudo sobre como o clima regional e as condições pluviais, associados a ocupação desordenada, podem recondicionar a funcionalidade das bacias hidrográficas urbanas, deflagrando por muitas vezes, episódios extremos catastróficos, relacionados a dinâmica da superfície. Dessa forma, objetiva-se analisar as condições pluviométricas e o histórico de eventos extremos que causaram movimentos de massa e inundações nas bacias urbanas do Rio Grande e Rio Anil, na Baixada de Jacarepaguá, no município do Rio de Janeiro.

\section{EVENTOS PLUVIAIS EXTREMOS E INTERAÇÕES EM BACIAS URBANAS}

A interferência de eventos pluviométricos extremos na dinâmica hidrossedimentológica de bacias urbanas e as implicações de tais processos têm sido trabalhada por diversos autores. Dentre eles, Marques (1990) trata da contribuição dos rios no aporte dos sedimentos das encostas para as baixadas litorâneas ocupadas pelo uso urbano, tendo como agente deflagrador desse processo a quantidade de chuvas em ambientes tropicais. Thomas (2000) relaciona a capacidade de mobilização dos sedimentos pelos fluxos intensificados durante as estações chuvosas, e argumenta que durante esses períodos a sensibilidade das bacias hidrográficas é aumentada, o que pode ser observado no aumento da frequência e magnitude dos fenômenos deflagrados por eventos climáticos extremos.

No modelo de análise espacial de bacias hidrográficas, apresentado por Harvey (2002), o autor comprova que a dinâmica desses sistemas é comandada pelos tipos de sedimentos produzidos, acumulados e/ou arrastados pela força das correntes induzidas por processos pluviais, mostrando como a morfologia das encostas e da rede de drenagem respondem às mudanças climáticas. $\mathrm{E}$, em seu modelo de análise temporal, o autor identifica que a eficiência energética da bacia está diretamente relacionada ao aumento da precipitação pluvial e ao volume de materiais sólidos arrastados e depositados nas áreas a jusante durante a ocorrência de eventos extremos.

Corroborando com os estudos apresentados, Fryirs (2013) aponta que, ao relacionar a pluviosidade com o histórico de eventos erosivos e hidrológicos, é possível avaliar a sensibilidade das áreas de encosta, vales, canais e 
planícies fluviais à ocorrência de distúrbios climáticos. Tais correlações são realizadas por meio da identificação da origem dos fluxos e dos tipos de materiais produzidos, arrastados e depositados ao longo do sistema ambiental como um todo.

Já Silva et al. (2003) destacam que, em áreas urbanas, predominam os processos decorrentes da concentração de fluxos devido a maior exposição dos solos, alta impermeabilização e à precariedade do sistema de drenagem. A exposição dos solos junto a alta impermeabilização do meio urbano faz com que a maior parte das águas precipitadas não seja interceptada ou infiltrada nas bacias. Com isso, mesmo quando há menores índices de precipitação, os fluxos de água escoam em grande volume e velocidade, gerando nas encostas o aumento da sensibilidade à movimentos de massa. Estes mesmos fluxos (rápidos e volumosos), ao alcançarem os canais fluviais, muitas vezes são mais intensificados devido a retificação e canalização das calhas dos rios, gerando fenômenos inundações de grandes proporções (TUCCI, 2003; BOTELHO e SILVA, 2004).

\section{METODOLOGIA}

O presente trabalho parte inicialmente de uma caracterização sobre as bacias do Rio Grande e Anil, no contexto dos aspectos físicos e dos problemas gerados pela ocupação urbana. Sobre o meio físico, foi feita uma caracterização geral, com destaque para os aspectos relativos as condições climáticas locais e sobre a atuação dos principais sistemas atmosféricos regionais. No que tange a ocupação, foi realizado o levantamento de informações bibliográficas, apresentando de maneira breve e objetiva alguns dos principais problemas gerados pelos padrões de urbanização encontrados na zona oeste carioca.

Num segundo momento foi feita a análise da precipitação e sua correlação com informações históricas acerca dos episódios pluviométricos e geomorfológicos registrados nas bacias do Rio Grande e Anil. Esta etapa foi realizada através dos seguintes processos:

i. análise da pluviosidade foi realizada com uso dos dados de precipitação anual e mensal, registrados entre os anos de 2011 a 2017, nas três estações pluviométricas do Sistema Alerta Rio localizadas nas bacias de drenagem do Rio Grande e do Rio Anil (município do Rio de Janeiro): estação Cidade de Deus, Tanque e Grajaú - Jacarepaguá.

ii. comparação entre os valores pluviométricos registrados nas estações Jacarepaguá/Cidade de Deus e Jacarepaguá/Tanque e Grajaú com os critérios de enquadramento de eventos pluviais significativos, de acordo com a Fundação Geo Rio;

iii. análise da precipitação média anual de cada ano estudado (de 2011 até 2017) e da série de sete anos de acordo com a análise isolada e conjunta dos dados das três estações meteorológicas analisadas. 
Para esses dados, além de avaliações quantitativas (apresentadas por tabelas), foi realizada a modelagem da distribuição geográfica da precipitação nas bacias em estudo, com uso de ferramentas de interpolação (IDW) geoespacial, disponíveis em Sistemas de Informações Geográficas (SIG), como o programa ArcGis 10.5 (utilizado para esse estudo.

iv. análise da precipitação média mensal do período entre 2011 a 2017 nas três estações pluviométricas. As análises mensais foram comparadas com os registros dos valores máximos de precipitação ocorridos em 24 horas durante os eventos extremos;

v. análise da precipitação total nas bacias por meio do cálculo da média anual, entre 2011 e 2017 para as três estações meteorológicas.

Os dados de chuva, obtidos da Sistema Alerta Rio foram relacionados às estatísticas de escorregamentos e ao de volume dos materiais mobilizados nos bairros que pertencem as bacias do Rio Grande e Anil, e aos relatórios anuais de chuvas e escorregamentos na cidade do Rio de Janeiro. Estes relatórios estão disponíveis no site da Fundação GeoRio (http://www.sistema-alerta-rio.com.br/documentos/relatorios-de-chuva/), compondo informações sobre as tipologias de movimentos de massa que tem ocorrido no município do Rio de Janeiro desde 2005. Esses dados foram correlacionados a informações obtidas de outras bibliografias, tais como Brandão (2009) e Ribeiro et al. (2014).

\section{CARACTERIZAÇÃO DAS BACIAS DO RIO GRANDE E RIO ANIL}

As bacias do Rio Grande e do Rio Anil estão localizadas entre as latitudes $22^{\circ} 53^{\prime}$ a $22^{\circ} 59^{\prime}$ do hemisfério sul, e longitudes $43^{\circ} 28^{\prime}$ a $43^{\circ} 17^{\prime}$ do hemisfério ocidental, na macrobacia da Baixada de Jacarepaguá, zona oeste litorânea do município do Rio de Janeiro, Brasil.

Ambos os sistemas de drenagem abrangem a captação de fluxos oriundos das altas encostas do Maciço da Pedra Branca, à oeste, e do Maciço da Tijuca, à leste, convergindo para a planície de Jacarepaguá, onde os cursos d'águas percorrem grandes extensões, com áreas urbanas densamente povoadas (CARVALHO, 2013; 2017). Em períodos de alta pluviosidade, a energia dessas bacias é intensificada pelo grande volume de fluxos de água em direção a baixada, aumentando a ocorrência de processos erosivos e hidrológicos.

Assim sendo, a Figura 1, representa o mapa de localização das bacias analisadas (bacia do Rio Grande e Rio Anil), assim como as respectivas estações meteorológicas do Sistema Alerta Rio. 
Figura 1. Mapa de localização das estações meteorológicas nas bacias de análise: bacia do Rio Grande e bacia do Rio Anil, no município do Rio de Janeiro.

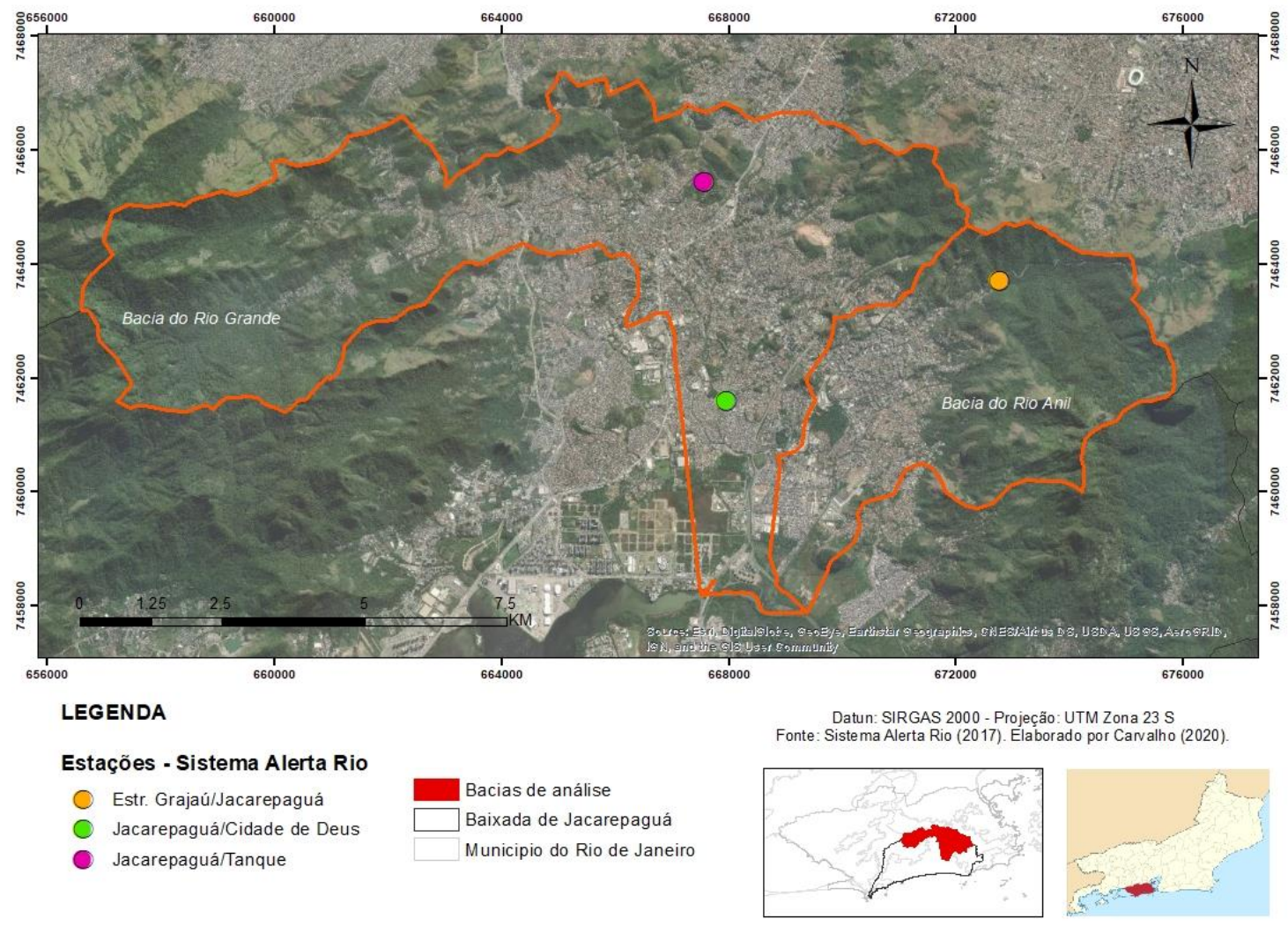

Fonte: elaboração própria.

\section{Contexto climático regional}

Nas bacias do Rio Grande e Anil o clima é influenciando pelo sistema de circulação tropical regional, que de acordo com Brandão e Brito (2009), se enquadra como Tropical Marítimo, devido a sua proximidade com o mar. Junto a esse sistema de circulação secundária, as características físico-ambientais das bacias de estudo (como as variações altimétricas, orientação das vertentes, cobertura vegetal, etc) influenciam no microclima, insolação, umidade relativa e sensação térmica local (COSTA, 2006; RIBEIRO, 2013).

A distribuição espacial e temporal das chuvas na região é irregular e se mantêm com temperaturas sempre mais elevadas que $20^{\circ} \mathrm{C}$ (VALLEJO et al., 2009; RIBEIRO, 2013). Entretanto, a aproximação dos Maciços da Tijuca, a leste e nordeste, e da Pedra Branca, a oeste e noroeste, favorecem a condensação e saturação da umidade, aumentando a incidência de chuvas nas cabeceiras de drenagem das bacias. Por esse motivo, o comportamento climático nas áreas de encosta é classificado principalmente em função da altitude, do índice de vegetação, da maritimidade e das posições das encostas (a barlavento ou sotavento).

As condições geomorfológicas locais favorecem a retenção da umidade e, portanto, aumentam a sensibilidade do sistema a sofrer processos erosivos e hidrológicos como os movimentos de massa e as inundações (RIBEIRO, 2013). No entanto, Ribeiro (2013) ressalta em suas pesquisas a dificuldade de se determinar com precisão os fatores que 
influenciam a ocorrência de tais eventos na Baixada de Jacarepaguá devido a carência de estações pluviométricas nos Maciços da Pedra Branca e da Tijuca.

Os tipos climáticos e suas características interferem na dinâmica superficial das bacias na medida em que a magnitude e a distribuição das chuvas formam fluxos de água de diferentes intensidades.

\section{Ocupação urbana e seus efeitos nas bacias do Rio Grande e Rio Anil}

A cidade do Rio de Janeiro tem por característica o histórico de expansão sobre os ecossistemas que ocupavam as baixadas litorâneas, o entorno dos maciços e suas encostas durante diferentes ciclos econômicos e avanço da ocupação urbana, particularmente para a direção oeste, onde se situa a Baixada de Jacarepaguá (COSTA, 2002; FREITAS et al., 2005). É nesse contexto que se inserem as mudanças no uso da terra e o avanço do processo de urbanização nas bacias do Rio Grande e do Rio Anil, na Baixada de Jacarepaguá, zona oeste do município carioca.

Assim, a partir dos dados de literatura consultados, pode-se afirmar que, apesar da existência do histórico de situações de irregularidades, a ocupação urbana nas bacias do Rio Grande e Anil foi se adensando primeiro nas médias e baixas encostas e posteriormente, também nas planícies e vales fluviais. Este processo só não conseguiu se perpetuar de fato nas altas encostas dessas bacias devido a criação das Unidades de Conservação: Parque Nacional da Tijuca e Parque Estadual da Pedra Branca (COSTA, 2002; CARVALHO, 2017). No entanto, é observado que nas áreas das bacias do Rio Grande e Anil, próximas aos limites dos Parques, o processo de urbanização acarretou a rápida degradação dos ecossistemas e alterações na morfologia da paisagem devido ao desmatamento e impermeabilização de encostas e vales.

Fora das Unidades de Conservação, as alterações ambientais vão muito além do desordenamento da ocupação e impermeabilizações. Ganha destaque as mudanças causadas pelas obras de drenagem, que vem sendo executadas na macrobacia da Baixada de Jacarepaguá desde 1940. Essas obras tinham como objetivo acelerar o escoamento das águas e permitir a ocupação das áreas próximas às margens dos rios e nos terrenos embrejados. E, por isso, daquela época em diante, vários rios da Baixada de Jacarepaguá, com destaque para os rios principais das bacias em estudo, passaram por um aprofundamento da calha, canalizações, retificações e, até mesmo, redirecionamento dos seus fluxos, que são o caso das bacias em estudo (MARQUES, 1990; FERREIRA E CUNHA, 1996; CARVALHO, 2013). É justo acrescentar que a drenagem das bacias ampliou a possibilidade de ocupação dos seus terrenos, mas também deve ser colocado que o impacto desta atividade aumentou os riscos de inundações nas áreas próximas aos rios, além de intensificar outros fenômenos como o assoreamento da Lagoa do Camorim, conforme evidenciado por Marques (1990) e Carvalho (2013; 2017).

Assim, da cota 100 m em direção a jusante das bacias do Rio Grande e Anil, onde são estabelecidos os limites das Unidades de Conservação, a cobertura vegetal vai sendo substituída por diferentes tipos de ocupação urbana: 
residências, comércio, serviços, indústrias e lazer. Esse processo vem ocorrendo (e se intensificando) principalmente ao longo dos últimos setenta anos. $\mathrm{E}$, diante do exposto, foi observado que os impactos implicaram na intensificação do escoamento superficial, reflexo do aumento do desmatamento e das impermeabilizações devido a drástica redução ou anulação da infiltração das águas nos solos (MARQUES, 1990; FERREIRA E CUNHA, 1996; COSTA, 2002).

Cabe, porém, ressaltar que os impactos acumulativos desse processo acelerado de urbanização não se restringem a ocupações de baixa renda, mas se estendem a outros segmentos da sociedade, indicando que o que falta é a implementação de políticas públicas territoriais capazes de conduzir o processo de ocupação urbana integrada a um planejamento e gerenciamento dos aspectos ambientais (MARQUES, 1990; COSTA, 2002; CARVALHO, 2013, RIBEIRO, 2013).

\section{RESULTADOS}

\section{Análise da pluviosidade e histórico de eventos extremos}

Por meio da análise comparativa entre as três estações no período de 2011 a 2017, foi constatado que a média anual da pluviosidade no período de sete anos foi menor na estação Jacarepaguá/Cidade de Deus (planície do Rio Grande), apresentando valores de 929,1 mm/ano, e maior na estação Grajaú/Jacarepaguá (nas altas vertentes da bacia do Rio Anil, Maciço da Tijuca), com valores médios anuais de 1208,9mm/ano. Na estação Jacarepaguá/Tanque foi registrado a média anual de 963,3 mm/ano, valor relativamente próximo, porém mais elevado, da média anual da estação Jacarepaguá/Cidade de Deus (Tabela 1).

Tabela 1. Precipitação Média anual (para cada estação individual e em conjunto com as três estações) e total entre o período de 2011 a 2017 (para cada estação individual e em conjunto com as três estações)

\begin{tabular}{|c|c|c|c|c|c|c|c|c|}
\hline Estações pluviométricas & 2011 & 2012 & 2013 & 2014 & 2015 & 2016 & 2017 & TOTAL \\
\hline Jacarepaguá/Tanque & 1044,2 & 924,2 & 1547,4 & 723,6 & 717,4 & 981 & 805,0 & 963,3 \\
\hline Jacarepaguá/Cidade de Deus & 946,8 & 906,8 & 1309,8 & 767,2 & 783,2 & 901,8 & 888,0 & 929,1 \\
\hline $\begin{array}{l}\text { Est. Grajaú/Jacarepaguá } \\
\text { Média de chuvas (Dados das }\end{array}$ & 1262,2 & 1050,4 & 1643,4 & 1025,6 & 895,2 & 1584 & 1001,6 & 1208,9 \\
\hline três estações) & 1316,05 & 1223,35 & 1628,4 & 1132,6 & 1102,7 & 1370,7 & 1177,9 & 1033,8 \\
\hline
\end{tabular}

Considerando a média dos valores totais anuais das três estações pluviométricas, observou-se que, entre o período de 2011 a 2017, a quantidade média anual de chuvas registradas nas bacias do Rio Grande e Anil foi em torno de 1033,88 mm/ano (Tabela 1). A partir desses dados constata-se a relevância da localização e registros da estação Grajaú/Jacarepaguá para análise da pluviosidade na bacia do Rio Anil e sua influência na planície da bacia do Rio Grande. Nessa estação foram registrados os maiores valores pluviais totais e médios, o que demonstra que a altitude é, de fato, 
um condicionante de extrema relevância na distribuição das chuvas, pois conforme se eleva a altitude da bacia, aumenta a quantidade de água que entra pela precipitação pluvial no sistema. Tais constatações podem ser observadas através da Figura 2, que ilustra o comportamento geográfico das chuvas, baseado na modelagem espacial os valores médios anuais dos anos de 2011 a 2017 e média anual do período ade análise (sete anos) (Figura 2).

Figura 2. Modelagem da distribuição das chuvas entre 2011 a 2017 nas bacias do Rio Grande e Rio Anil: valores médios anuais e média total do período analisado
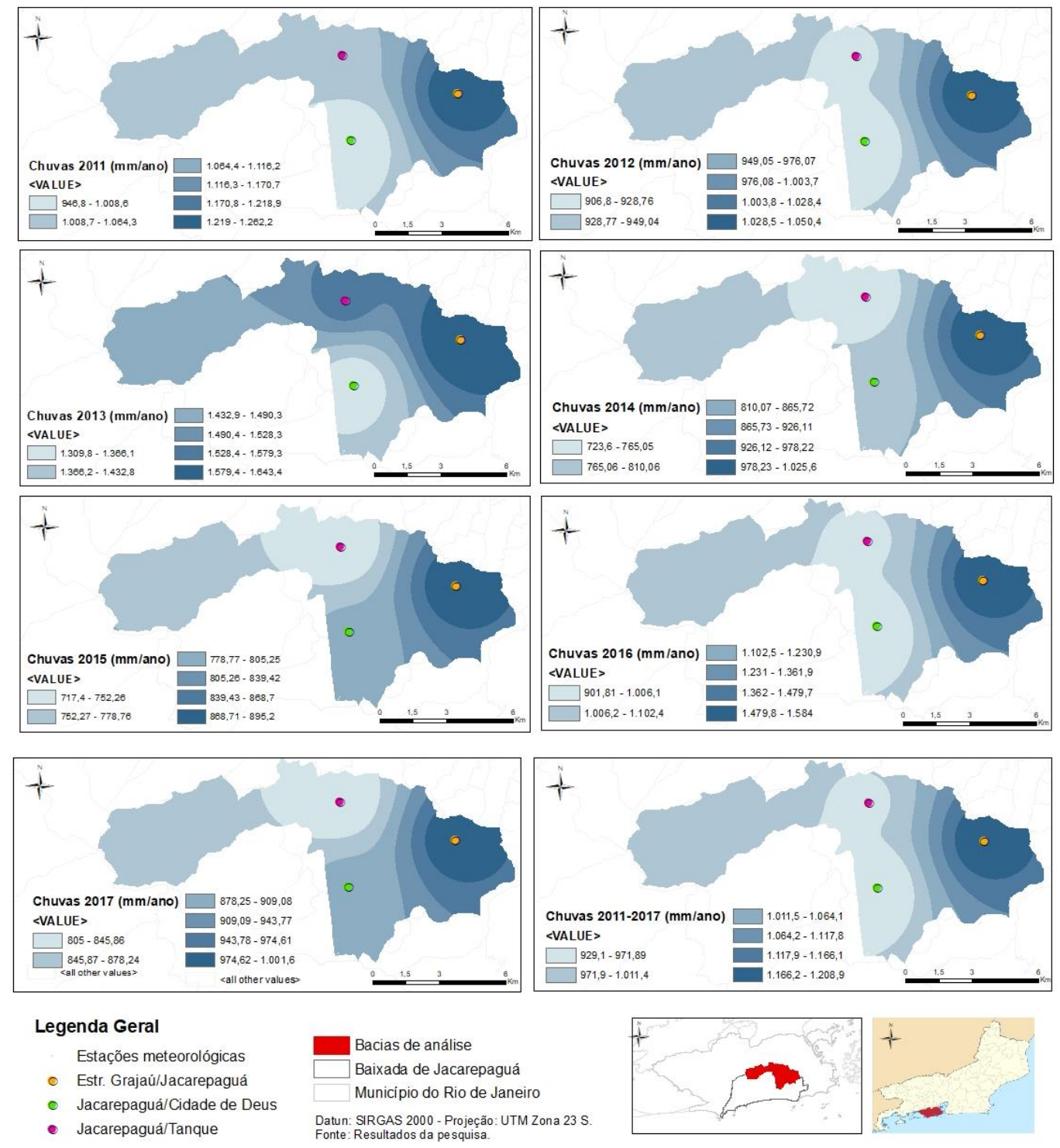

Fonte: elaboração própria.

Contudo, destaca-se que é provável que, caso houvesse também o registro da pluviosidade das altas altitudes na bacia do Rio Grande, a pluviosidade média anual fosse maior. Por isso, é importante que a Geo-Rio e outras instituições responsáveis por levantamento de dados meteorológicos, considerem também a instalação de estações pluviométricas 
nas altas encostas do Maciço da Pedra Branca, possibilitando maior acurácia na modelagem dos dados pluviométricos dessa área para monitoramento de eventos extremos e perigos associados a movimentos de massa e inundações.

Em relação à média mensal entre 2011 e 2017, o resultado da análise dos dados comprovam que a maior pluviosidade se concentra no verão nos meses de dezembro (124,1 mm/mês), janeiro (163,5 mm/mês) e março com valores de 142,2 mm/mês. O mês de fevereiro apresenta uma queda significativa para o período de verão, com média mensal de $75,3 \mathrm{~mm} /$ mês. O período de menor pluviosidade ocorre no inverno, nos meses de julho, com valores de 44,6 $\mathrm{mm} / \mathrm{mês}$, e agosto, com médias mensais entre $31,6 \mathrm{~mm} / \mathrm{mês}$, conforme apresentado pela Tabela 2 e pela Figura 3 .

Tabela 2. Média mensal das chuvas entre os anos de 2011 e 2017 ( $\mathrm{mm} / \mathrm{mês}$ ) das três estações pluviométricas, localizadas nas bacias do Rio Grande e Anil

\begin{tabular}{|c|c|c|c|c|}
\hline Mês & $\begin{array}{l}\text { Est.Jacarepaguá/ } \\
\text { Tanque }\end{array}$ & $\begin{array}{l}\text { Est. Jacarepaguá/ Cidade } \\
\text { de Deus }\end{array}$ & $\begin{array}{l}\text { Est.Grajaú/ } \\
\text { Jacarepaguá }\end{array}$ & $\begin{array}{l}\text { Média mensal } \\
\text { (mm/mês) }\end{array}$ \\
\hline Janeiro & 149,9 & 130,6 & 210,0 & 163,5 \\
\hline Fevereiro & 81,9 & 67,6 & 73,4 & 74,3 \\
\hline Março & 133,4 & 128,8 & 165,7 & 142,7 \\
\hline Abril & 92,5 & 87,9 & 119,7 & 100,0 \\
\hline Maio & 55,1 & 63,0 & 74,7 & 64,3 \\
\hline Junho & 67,5 & 89,7 & 97,9 & 85,0 \\
\hline Julho & 32,7 & 42,6 & 58,5 & 44,6 \\
\hline Agosto & 28,2 & 26,0 & 40,5 & 31,6 \\
\hline Setembro & 50,7 & 45,7 & 65,0 & 53,8 \\
\hline Outubro & 44,7 & 45,8 & 57,5 & 49,3 \\
\hline Novembro & 101,3 & 88,7 & 116,6 & 102,2 \\
\hline Dezembro & 135,3 & 107,8 & 129,2 & 124,1 \\
\hline
\end{tabular}

Fonte: elaboração própria.

Figura 3. Média mensal total das chuvas entre os anos de 2011 e 2017 (mm/mês) nas estações localizadas nas bacias do Rio Grande e Anil

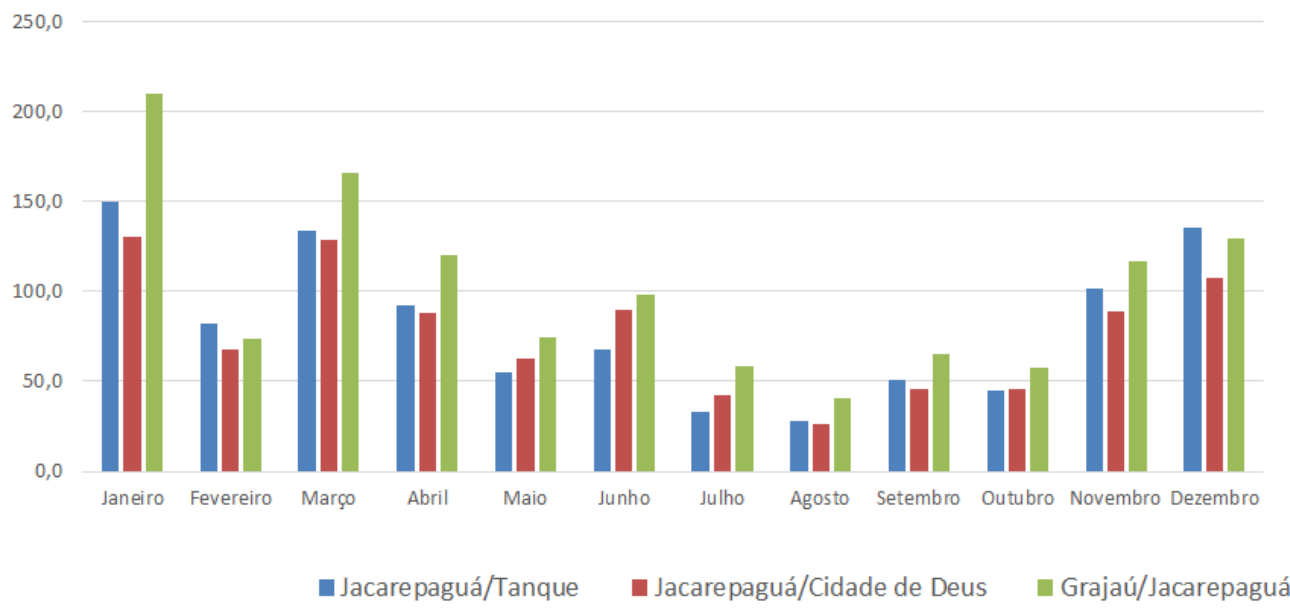

Fonte: elaboração própria. 
Cabe destacar que a climatologia da precipitação sobre a região sudeste do Brasil tem um importante componente que atua durante o verão e acompanha o ciclo anual das chuvas. Esse componente, conhecido com ZCAS (Zona de Convergência do Atlântico Sul), caracteriza-se como uma banda de nebulosidade e chuvas com orientação noroeste-sudeste que se estende desde a Amazônia até o Sudeste do Brasil e, com frequência, sobre o Atlântico Subtropical (CARVALHO E JONES, 2009). Embora essa característica seja observada em todos os verões, ocorrem variações importantes na organização espacial, na intensidade das chuvas e na circulação. Tais variações são responsáveis por diversas consequências ambientais, como eventos de precipitação intensa que trazem alagamentos, inundações e movimentos de massa.

Carvalho et. al. (2002), em estudo realizado no estado de São Paulo, constataram que a intensidade da ZCAS é essencial para a modulação de eventos extremos no estado, onde aproximadamente $65 \%$ dos eventos extremos ocorrem em associação a uma intensa atividade convectiva da ZCAS. Vários autores também mostraram que a intensificação da ZCAS está relacionada com outros sistemas, tais como os sistemas frontais e a Alta da Bolívia (FERREIRA ET. AL., 2004). O evento de chuvas extremas ocorrido em 2011, na Região Serrana do Rio de Janeiro, pode ser tomado como um importante exemplo recente no qual o padrão sinótico esteve associado à ZCAS. Assim sendo, um sistema eficaz de previsão das condições do tempo associadas a sistemas de alerta é de suma importância na avaliação de risco de desastres.

Portanto, considerando a análise dos dados pluviais das estações do Sistema Alerta Rio e seu contexto geográfico, verifica-se que a maior concentração de água precipitada nas bacias foi identificada, ao longo de todo ano (independente da média mensal), nas altas vertentes das bacias em estudo, com destaque para a bacia do Rio Anil. Assim, os perigos de eventos pluviais extremos associados a movimentos de massa e as inundações podem ocorrer em função das interações entre os fluxos de origem pluvial e fluvial que, de montante a jusante das bacias, se retroalimentam e se intensificam, sobretudo durante os meses de dezembro, janeiro e março. Nestes casos, eventos pluviométricos de grande intensidade desencadeiam o aumento dos fluxos superficiais nas encostas e canais de drenagem, que poderão ser mais ou menos sentidos pela população local, de acordo com o conjunto de características físicas-naturais, da fisionomia da ocupação e do uso da terra das bacias urbanizadas (HARVEY, 2002; THOMAS, 2000).

\section{Histórico de eventos extremos}

Na cidade do Rio de Janeiro o efeito das fortes chuvas e suas consequências socioambientais já fazem parte da história do município. Vários estudos têm sido realizados a fim de entender as relações entra a suscetibilidade natural do meio e a participação das atividades antrópicas na indução de processos como as inundações e os movimentos de massa.

Em 1953, ao avaliar o problema das inundações na cidade do Rio de Janeiro, Ruellan (1953 apud MARQUES, 1990, p. 9) afirma que: 
Quando ocorrem chuvas mais fortes é enorme o trabalho de sedimentação nas ruas da base de encostas e na baixada. Vêm-se reconstituir em pouco mais de uma hora as vezes as antigas lagunas e os antigos cursos d'água hoje desaparecidos da paisagem urbana. Essa reconstituição passageira da antiga rede de drenagem e das antigas lagoas, por ocasião de enchentes, é acompanhada de uma sedimentação cujo volume é preciso não subestimar, pois em consequência de uma única chuva violenta, há às vezes dezenas de toneladas de sedimentos a retirar (RUELLAN, 1953 apud MARQUES, 1990, p. 9).

Trabalhos como os de Amaral (1996) e Costa (2002) asseguram que, em termos comparativos o Maciço da Pedra Branca não possui tantos registros de movimentos de massa significativos como o Maciço da Tijuca. Fato que pode estar relacionado a ocupação mais tardia da zona oeste do que propriamente a estabilidade do meio físico.

Ao avaliar o risco de movimentos de massa, autores como Costa (2002) e Ribeiro (2013), afirmam que a maior suscetibilidade a eventos extremos nas proximidades dos Maciços da Tijuca e Pedra Branca, onde estão situadas as bacias de estudo, ocorre pelo conjunto dos aspectos físicos locais, relacionados a geologia, geomorfologia, aos tipos de solos e a distribuição de chuvas. Para Ribeiro (2013) o conjunto de características físicas que se estabelecem (principalmente a partir da cota 50m) em toda a vertente leste do Parque Pedra Branca, faz com que praticamente toda essa área seja suscetível à escorregamentos.

Nessa mesma linha, porém com foco direcionado a ocorrência de inundações, Brandão (2009) ressalta que a redução das áreas verdes no município do Rio de Janeiro tem colaborado com o aumento dos processos erosivos "provocando e contribuindo para intensificar as periódicas inundações" (BRANDÃO, 2009, p. 94). A autora apresenta um levantamento histórico dos principais episódios pluviométricos que causaram inundações e escorregamentos no município.

De acordo com Brandão (2009), nas décadas de 1980 e 1990, dois eventos de grande proporção podem ser destacados:

- No dia 12/04/1985, quando a precipitação diária chegou a $144 \mathrm{~mm} /$ dia provocando inundações dos canais fluviais e causando a morte de duas pessoas.

- No dia 13/02/1996, que choveu $220 \mathrm{~mm}$ em apenas 8 horas, causando a morte de 59 pessoas e 1500 desabrigados, a maioria de Jacarepaguá.

O último evento registrado merece destaque. Na bacia do Rio Grande, a catástrofe de fevereiro de 1996 desencadeou fortes movimentos de massa, enxurradas e inundações que levaram a morte de 59 pessoas, deixando 1500 desabrigadas. No Maciço da Tijuca, somente nas vertentes sul e sudoeste foram registrados 38 escorregamentos de diferentes magnitudes e naturezas. Enquanto no Maciço da Pedra Branca foram identificadas 500 cicatrizes de erosão ao longo das encostas e vales em decorrência de escorregamentos e desmoronamentos (BRANDÃO, 2009).

Costa (2002) e Costa (2006) ressaltam que essas cicatrizes (Figura 4) foram originadas em áreas florestadas e que as encostas das bacias do Rio Grande, Camorim e Sacarrão foram as mais atingidas. Nas áreas de planície, alguns trechos 
do leito original do Rio Grande e de vários de seus afluentes deixaram de existir, nivelando-se aos terrenos marginais. Na comunidade Cidade de Deus várias pessoas perderam seus barracos por conta das inundações, assim como na comunidade do Rio das Pedras. Nas Figuras 4 e 5 é possível observar no Bairro da taquara os carros amontoados em virtude da correnteza das águas e o volume de sedimento depositado durante o evento na zona oeste da cidade.

Figura 4. Cicatrizes de Erosão na bacia do Rio Grande.
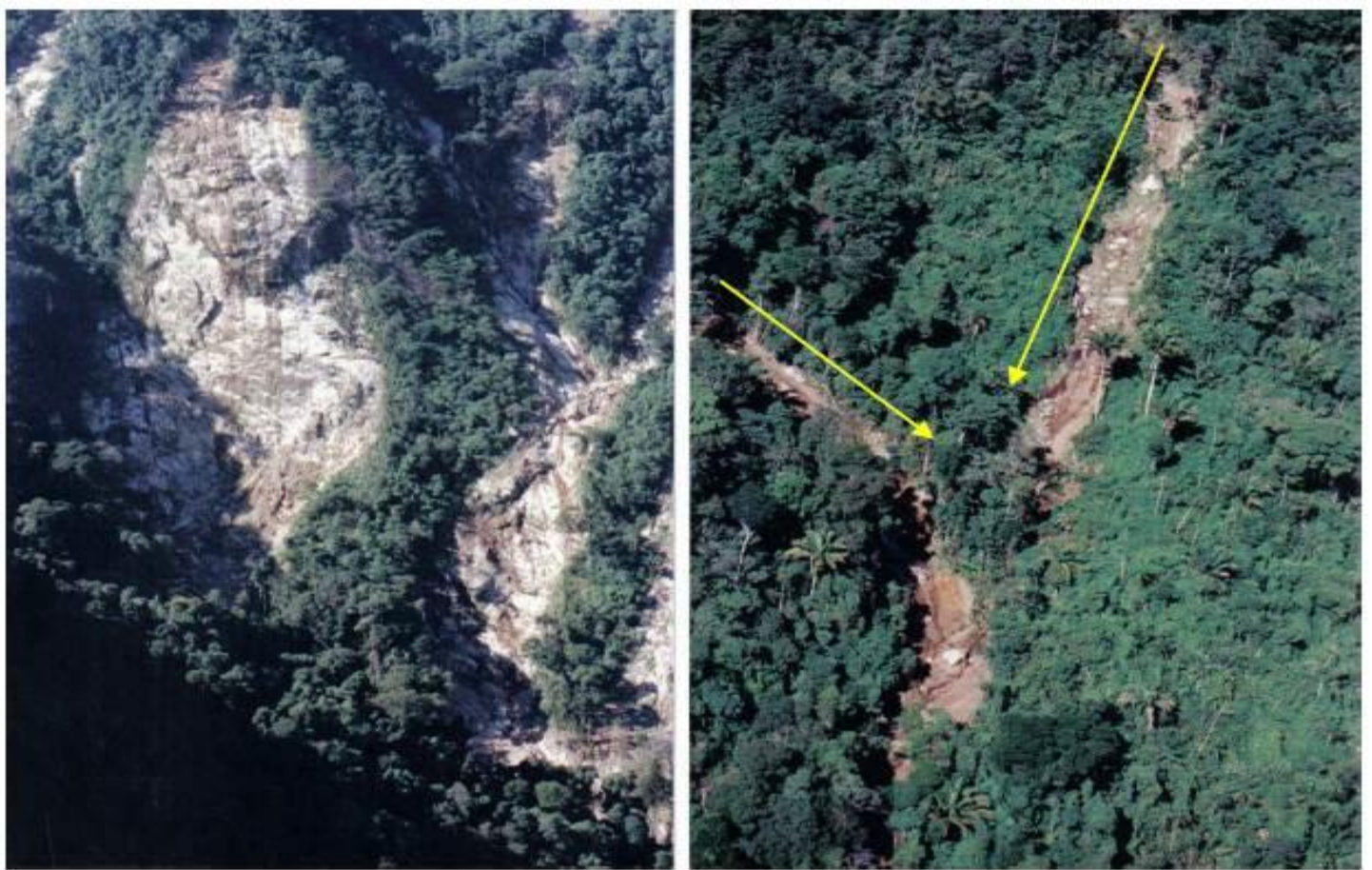

Nota: Na foto da esquerda - cicatrizes de erosão nas cabeceiras do Rio Grande, ocorridas durante as chuvas de 1996: Movimentos de massa na ruptura de declive, com descida de material rochoso. Foto da direita detalhes do escorregamento de lama em duas direções, trazendo árvores, detritos e blocos rochosos pelas encostas da bacia do Rio Grande (Maciço da Pedra Branca). Fonte: COSTA (2006).

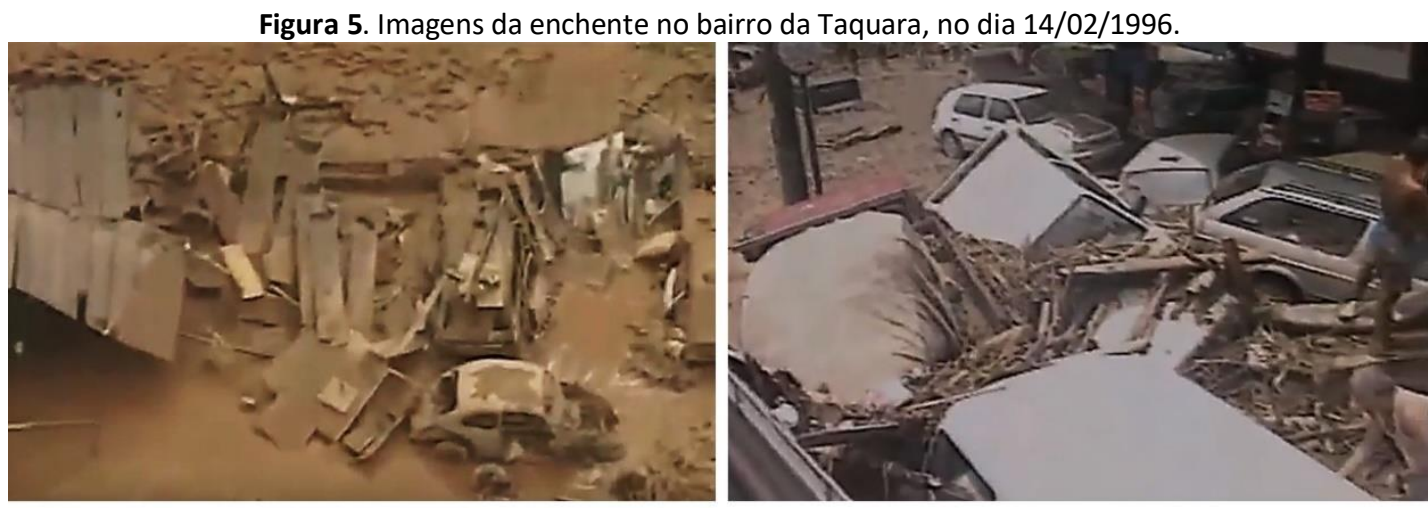

Fonte: Imagens da TV Globo-Jornal Nacional (1996).

Um ano após a tragédia, em 1997, o Governo Municipal do Rio de Janeiro instalou estações pluviométricas em vários pontos da cidade através do Sistema Alerta Rio, com o objetivo de realizar o monitoramento sistemático da 
intensidade das chuvas, identificar a ameaça de eventos, e alertar "a população sempre que houver previsão de chuvas intensas que possam gerar inundações de vias públicas e/ou acidentes geotécnicos em encostas" (ALERTA RIO, 2018).

A partir da instalação dessas estações pluviométricas, os registros de eventos extremos no município do Rio de Janeiro passaram a ser estudados de maneira sistemática pela Fundação Geo-Rio, órgão responsável pelo gerenciamento do Sistema Alerta Rio. De acordo com a metodologia adotada pela Geo-Rio, os eventos pluviométricos definidos como significativos são os que podem deflagrar acidentes geológico-geotécnicos. Na Tabela 3 observa-se o enquadramento da macrobacia de Jacarepaguá para os eventos pluviais significativos segundo os dados das estações meteorológicas.

Tabela 3. Critérios para enquadramento de evento pluviais significativo segundo as medições das estações meteorológicas do Sistema Alerta Rio na bacia hidrográfica de Jacarepaguá, cidade do Rio de Janeiro

\begin{tabular}{cccc}
\hline $\begin{array}{c}\text { Bacia } \\
\text { hidrográfica }\end{array}$ & Pluviosidade & \\
\hline \multirow{2}{*}{$\begin{array}{c}\text { Jacarepaguá } \\
\text { Em pelo menos } 3 \text { estações } \\
\text { pluviométricas }\end{array}$} & $\geq 20 \mathrm{~mm} / \mathrm{h}$ & $\geq 40 \mathrm{~mm} / \mathrm{h}$ \\
& Em pelo menos 2 estações & pluviométricas & $\begin{array}{c}\text { Em pelo menos } 1 \text { estação } \\
\text { pluviométrica }\end{array}$ \\
\hline
\end{tabular}

Fonte: Adaptado da FUNDAÇÃO GEO-RIO (2012).

Assim, baseado em registros documentais, na classificação da Fundação Geo-Rio, e no levantamento dos dados pluviométricos do Sistema Alerta Rio, foi elaborado uma tabela com a média pluviométrica das chuvas máximas que incidiram durante 1 hora (Tabela 4) nas três estações localizadas nas bacias do Rio Grande e Anil (Tanque, Cidade de Deus e Grajaú-Jacarepaguá) durante os principais episódios de chuvas catastróficas que ocorreram no Estado e atingiram a cidade do Rio de Janeiro entre 2001 e 2016.

Tabela 4. Relação entre as chuvas máximas e registros anuais dos eventos pluviais extremos que atingiram a bacia do Rio Grande e Anil, município do Rio de Janeiro, entre 2001 - 2016*.

\begin{tabular}{ccccc}
\hline \multirow{2}{*}{$\begin{array}{c}\text { Ano de ocorrência de } \\
\text { eventos extremos }\end{array}$} & $\begin{array}{c}\text { Mês de } \\
\text { referência }\end{array}$ & \multicolumn{2}{c}{$\begin{array}{c}\text { Chuva máxima em 1 hora }(\mathbf{m m}) \text { nas Estações Pluviométricas } \\
\text { localizadas nas bacias em estudo }\end{array}$} \\
\cline { 3 - 5 } 2001 & Dezembro & 42,40 & 24,80 & Grajau-Jacarepaguá* \\
2002 & Fevereiro & 23,20 & 22,20 & Sem registro \\
2007 & Janeiro & 23,00 & 21,00 & Sem registro \\
2010 & Abril & 42,40 & 40,20 & Sem registro \\
2011 & Janeiro & 18,80 & 22,20 & 39,00 \\
2013 & Janeiro & 54,8 & 32,6 & 20,60 \\
\hline
\end{tabular}

Nota: Nos anos 2003, 2004, 2005, 2006, 2008, 2009, 2012, 2014, 2015, 2016, 2017 e 2018 não houve registro de eventos extremos nas estações pluviométricas estudadas, segundo os critérios de enquadramento da GEO-RIO. * A ausência de valores nos anos de 2001, 2002 e 2007 na estação Grajaú-Jacarepaguá se justifica devido a instalação da mesma ter ocorrido somente em maio de 2010. Fonte: Adaptado da FUNDAÇÃO GEO-RIO (2016) e do ALERTA RIO (2018). 
Entre os dias 22 e 24 de dezembro de 2001 as chuvas provocaram a morte de 43 pessoas em todo o Estado do Rio de Janeiro, e entre janeiro e fevereiro do ano seguinte, 88 pessoas foram vítimas de inundações e escorregamentos.

Novamente, em janeiro de 2007 as chuvas intensas deixaram cerca de 12.000 pessoas desabrigadas em vários municípios fluminenses (BIOGIL, 2012).

Três anos depois, em 06 de abril de 2010 o temporal causou a morte de 103 pessoas, 56 feridos e 1410 pessoas desabrigadas no município do Rio de Janeiro. Este foi considerado o evento extremo mais intenso vivenciado na cidade nos últimos 44 anos, com uma precipitação pluvial de 288 milímetros em menos de 24 horas (ISTOÉ, 2010; BIOGIL, 2012).

No ano seguinte, em 11 de janeiro de 2011 uma chuva equivalente a um mês de precipitação atingiu a cidade carioca e toda a Região Serrana do Estado. Na bacia do Rio Grande e Anil as estações registraram eventos de pluviosidade significativa, mas a catástrofe se concentrou nas cidades de Petrópolis, Teresópolis, Nova Friburgo, Itaipava, Bom Jardim e Sumidouro, contabilizando um total de 379 vítimas (BIOGIL, 2012). Após esses eventos destaca-se a criação do Centro de Monitoramento e Alerta de desastres naturais - CEMADEN.

Em janeiro de 2013 a primeira chuva do ano trouxe problemas para a população residente nas bacias do Rio Grande e Anil. Em menos de 30 minutos as águas provocaram alagamentos nas casas e comércios nos terrenos próximos a Estrada do Pau Ferro em Jacarepaguá (CARIELLO \& REBELLO, 2013). Apesar do avanço da água e da lama depositada, não houve vítimas no local.

De acordo com os dados e informações analisados, até o ano de 2013, durante todos os eventos catastróficos ocorridos na última década na cidade e Estado do Rio de Janeiro, os registros de chuva nas estações pluviométricas das bacias em estudo indicaram a existência de riscos a população de diferentes magnitudes (FUNDAÇÃO GEO-RIO, 2013; ALERTA RIO, 2018). De acordo com as informações das Tabela 3 e 4 se observa que no período analisado houve três casos de pluviosidade maior ou igual a $20 \mathrm{~mm} / \mathrm{h}$ em duas estações meteorológicas e três casos (2001, 2010 e 2013) em que o alerta em apenas uma estação com valores iguais ou superiores a $40 \mathrm{~mm} / \mathrm{h}$ em pelo menos uma estação pluviométrica foi atingido.

Dos bairros que agregam as bacias do Rio Grande e Anil, até o ano de 2013, Jacarepaguá foi o que apresentou o maior número de ocorrências movimentos de massa (total de 91 ocorrências) e volume de material mobilizado. Durante dois eventos extremos a carga mobilizada foi maior do que $1000 \mathrm{~m}^{3}$, sendo que quarenta e três estiveram com material mobilizado entre 1 a $10 \mathrm{~m}^{3}$, trinta e cinco ocorrências entre 11 a $100 \mathrm{~m}^{3}$ e quatro registros com 101 a $1000 \mathrm{~m}^{3}$ de volume de material mobilizado. 
De acordo com os relatórios da Geo-Rio, entre os anos de 2010 e 2016 o volume de material mobilizado por movimentos de massa nos bairros abrangidos pelas bacias de estudo apresentou, principalmente, os seguintes aspectos: Deslocamento de blocos, escorregamento planar de blocos de rocha e solo coluvionar ou residual, rolamento de blocos, ruptura ou deslizamento de solo em talude e contenção - Figura 5 (FUNDAÇÃO GEO-RIO, 2005; 2006; 2008; 2009; 2011; 2011a; 2011b; 2012; 2012a; 2016).

Figura 5. Principais tipologias de movimentos de massa nas bacias do Rio Grande e Anil.

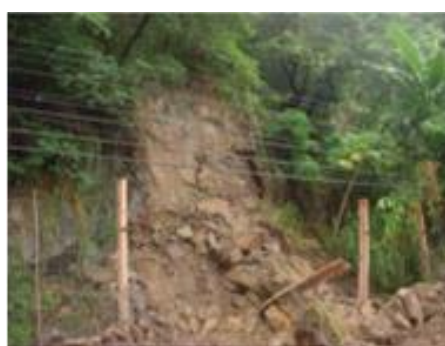

25/03/2005 - Deslocamento

de blocos contidos por

estrutura de impacto na

Estrada Grajaú-

Jacarepagui.
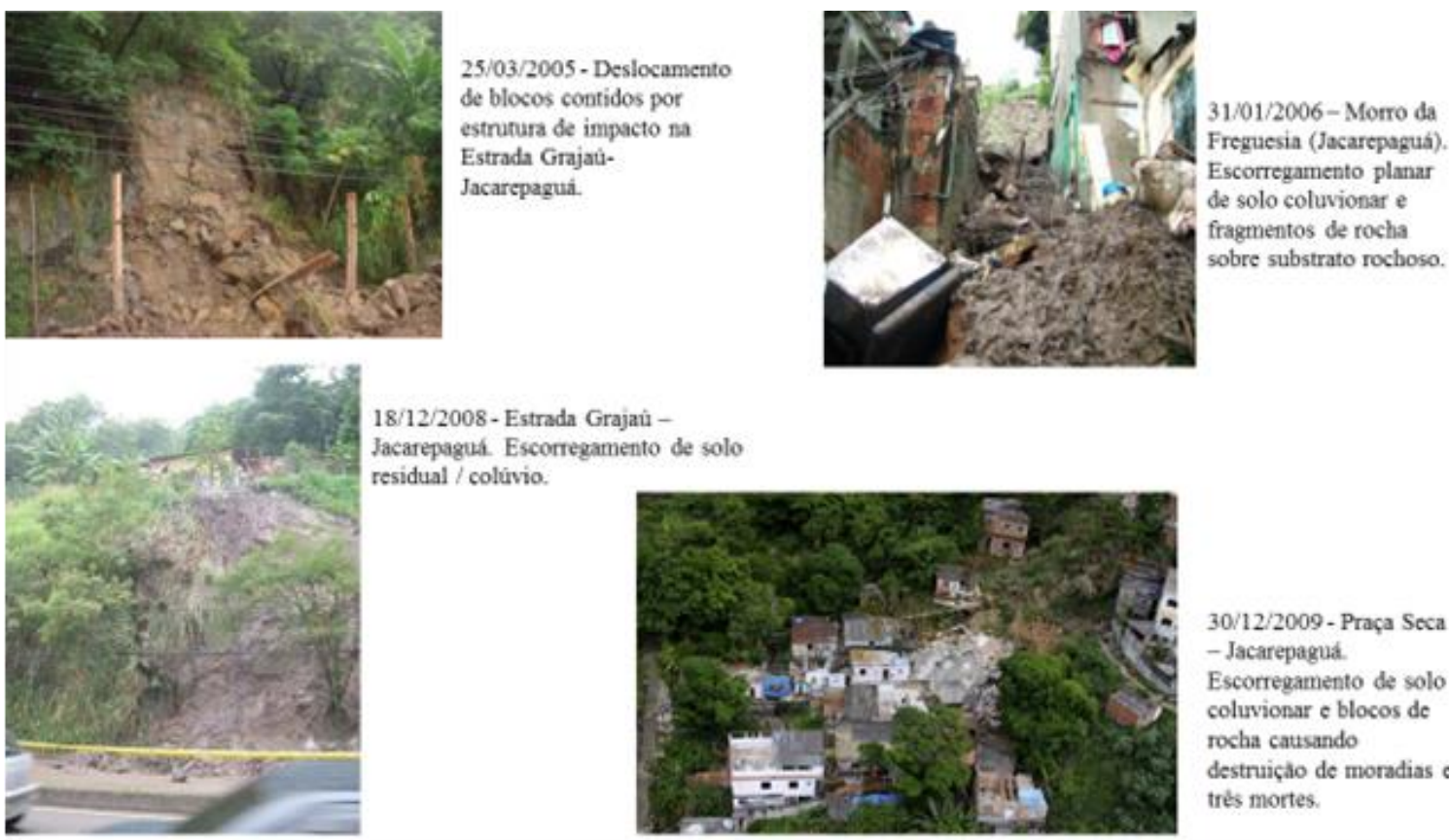

18/12/2008 - Estrada Grajaù -

Jacarepaguí. Escorregamento de solo residual / colúvio.

Fonte: FUNDAÇÃO GEO-RIO (2005, 2006, 2008, 2009).

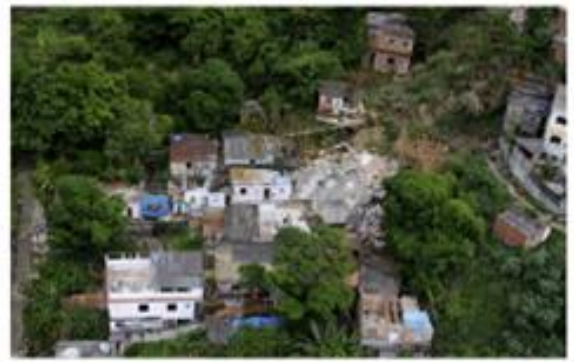

30/12/2009 - Praça Seca - Jacarepaguá.

Escorregamento de solo coluvionar e blocos de rocha causando

destruiçato de moradias c trè's mortes.

Apesar dos eventos descritos na Figura 6 não representarem eventos extremos e não estarem enquadrados nos critérios de evento pluviais significativos pela GEO-RIO, observa-se que menores índices pluviométricos podem ocasionar movimentos de massas pontuais em toda a cidade, sendo que por muita das vezes, estes eventos também possuem significativas perdas e danos a sociedade. O que vai de encontro com a classificação proposta por Armond e Sant'Anna Neto (2017), que considera que os eventos que deflagraram impactos relacionados ao espaço urbano podem ser considerados como episódios extremos a partir de uma análise geográfica que prioriza a observação de impactos dos eventos e não somente os valores que ultrapassam os padrões habituais.

Ao correlacionar a análise da pluviosidade com o histórico de episódios pluviais, organizado por Brandão (2009), e relatórios anuais de pluviosidade e escorregamentos publicados pela Geo-Rio, constata-se que, durante o verão (meses mais chuvosos) a força dos fluxos superficiais aumenta nas encostas e na rede de drenagem nos sistemas do Rio Grande e Anil, potencializando a ocorrência de eventos extremos e o 
encadeamento de seus efeitos. Pôde-se verificar também que as duas bacias são sensíveis a incidência de processos erosivos e hidrológicos (FUNDAÇÃO GEO-RIO, 2005; 2006; 2008; 2009; 2011; 2011a; 2011b; 2012; 2012a; 2016). E ainda, que essas bacias são propensas ao encadeamento dos fenômenos de movimentos de massa e inundações. A origem de um processo em determinada área pode desencadear outros processos a jusante, de proporções e efeitos distintos do fenômeno original, dado o conjunto de fatores físico-ambientais das bacias. Portanto, no baixo curso dos rios Grande e Anil e de seus afluentes, as lagoas e terrenos marginais, "encontram-se em situação de dependência quanto ao volume de água e sedimentos que recebem dos Maciços via canais fluviais" (MARQUES, 1990, p. 74).

Porém, apesar das chuvas intensas motivarem a ocorrência de eventos extremos, Marques (1990) avalia que a intensa ocupação urbana e o aumento populacional, que trouxeram rápidas transformações para a Baixada de Jacarepaguá, podem ter ampliado os riscos geomorfológicos.

Na mesma perspectiva, Ribeiro et al. (2014) estabelecem que existem relações diretas entre os valores mensais de pluviosidade, a ocupação, e os fenômenos hidrológicos intensos que ocorrem na Baixada de Jacarepaguá, em especial nas vertentes leste do Maciço da Pedra Branca, onde se situa a nascente do Rio Grande. Para os autores, movimentos de massa e inundações também podem ser desencadeados pela frequência das chuvas mensais até mais baixos em virtude do histórico de crescimento intenso e caótico das áreas urbanas. Para comprovar essa afirmação, Ribeiro et al. (2013) relacionaram os valores médios mensais das chuvas com as áreas de ameaça a ocorrência de eventos extremos, registrados pela Fundação Geo-Rio até o ano de 2010 , observando que $92 \%$ das cheias estão relacionadas a valores de pluviosidade mensal acima de 111 milímetros. Os autores concluíram que o crescimento da ocupação desordenada em áreas naturalmente sensíveis contribui para o aumento de sua instabilidade, desencadeando eventos simultâneos (RIBEIRO et al., 2014).

Assim sendo, se observa que o espaço urbano das bacias em análise são espaços de risco por excelência, sendo que existe uma susceptibilidade natural da região para as ocorrências de inundação, alagamentos e movimentos de massa que são potencializadas pelas mudanças ambientais antropogênicas em diferentes tipos de escala.

\section{CONSIDERAÇÕES FINAIS}

Verificou-se através deste estudo que a alta pluviosidade e o histórico de ocorrência de eventos extremos na cidade do Rio de Janeiro, aliados ao crescimento da população urbana e a ausência de planejamento no uso da terra, têm aumentado a magnitude dos eventos extremos e o risco de catástrofes causadas pela alta pluviosidade natural que ocorre nas bacias do Rio Grande e Anil, na região de Jacarepaguá. 
Estas bacias são representativas do contexto ambiental municipal, e atestam que durante os meses de verão, que são períodos de alta pluviosidade, o aumento dos fluxos superficiais das encostas em direção as planícies convergem para a rede de drenagem com forte intensidade, e são potencializados pelas formas de ocupação urbana irregular e adensadas nas encostas e vales fluviais. Com isso, ao longo do processo de ocupação, são registados cada vez mais catástrofes relacionadas a ocorrência de processos erosivos e hidrológicos.

Esse comportamento se justifica nas bacias urbanas (representadas neste trabalho pelas bacias do Rio Grande e Anil) pois, durante os períodos mais chuvosos, a energia disponível desses sistemas aumenta, intensificando a capacidade de produção e transporte de materiais, o que aumenta a sensibilidade do meio a ocorrência de movimentos de massa e inundações que historicamente vem sendo acompanhada de inúmeras perdas e danos à sociedade. É evidente e preocupante também a recente ocupação desordenada do Maciço da Pedra Branca onde, historicamente, sempre apresentou os menores números de ocorrência de movimentos de massa e inundação. Este fato tende a ser revertido na medida em que as alterações urbanas incidem de forma desordenada na bacia do Rio Grande, tal como foi (e tem sido) na bacia do Rio Anil. O aumento anual dos registros de movimentos de massa, enchentes e inundações, em número e intensidade nas bacias analisadas, junto ao registro das chuvas pelas estações pluviométricas, indicam o aumento de desastres climáticos nessas bacias aliada as formas de ocupação.

Destaca-se a importância das estações pluviométricas em diferentes posições altimétricas das bacias urbanas, de forma a permitir uma modelagem mais precisa da distribuição das chuvas e assim, possibilitar o maior controle das áreas de risco de desastres causados por eventos extremos. Com relação a essa questão, foi detectada uma certa carência de investimentos no sistema de monitoramento e alerta de eventos pluviométricos extremos, sendo que em diversas situações os dados apontaram a tomada de medidas públicas em caráter emergencial, ou seja, pós-desastres. Exemplos são a própria época de criação do Sistema Alerta Rio, pós desastre de 1996, e do Centro Nacional de Monitoramento e Alerta de Desastres Naturais (CEMADEN), pós desastre da Região Serrana do Rio de Janeiro, em 2011.

\section{REFERÊNCIAS}

ABREU, M. de. Geografia Histórica do Rio de Janeiro (1502 - 1700). Rio de Janeiro: Andrea Jakobson, 2011. 904 p.

ALERTA RIO. Estatística dos dados pluviométricos acumuladas mensais, registradas pelo sistema de alerta de chuvas da Prefeitura da Cidade do Rio de Janeiro até dezembro de 2016. Rio de Janeiro: Prefeitura Municipal, Centro de Operações Rio (COR), 2018. Disponível em < http://alertario.rio.rj.gov.br/?page_id=2 >. Acesso em 03 de abril de 2018.

AMARAL, C. P. do. Escorregamentos no Rio de Janeiro: Inventário, Condicionantes, Geologia e Redução do Risco. Tese (doutorado), Departamento de Engenharia Civil da PUC-Rio, Rio de Janeiro, 1996, 269 p.

ARMOND, N.B.; SANT'ANNA NETO, J.L. Entre eventos e episódios: ritmo climático e excepcionalidades para uma abordagem geográfica do clima no município do Rio de Janeiro. Revista Brasileira de Climatologia, ano 13, v. 20, jan/jul, p.5-28, 2017. 
BIOGIL. Enchentes Históricas no Brasil. 2012. Disponível em < http://biogilmendes.blogspot.com.br/2012/01/enchentes-historicasno-brasil.html>. Acesso em 29 de dez/2014.

BOTELHO, R. G. M.; SILVA, A. S. Bacia hidrográfica e qualidade ambiental. In: VITTE, A. C.; GUERRA, A. J. T. (Orgs.). Reflexões sobre a Geografia Física Brasileira. Rio de Janeiro: Bertrand Brasil, 2004, v.1, p. 153-192.

BRANDÃO, A. M. P. M. O clima urbano e enchentes na cidade do Rio de Janeiro. In: GUERRA, A. J. T.; CUNHA, S. B. (Orgs). Impactos Ambientais Urbanos no Brasil. 5a ed. Rio de Janeiro: Bertrand Brasil, p. 47-109, 2009.

BRANDÃO, A. M. P. M; BRITO; T. L. F. de. O microclima de Jacarepaguá/RJ: crescimento urbano e prováveis alterações climáticas em Jacarepaguá/RJ. In: Simpósio Brasileiro de Geografia Física E Aplicada, 13., Viçosa, 2009. Anais...Viçosa, 2009. p. 1-14.

CARIELLO, G.; REBELLO, P. Enchentes em Jacarepaguá, até quando? Primeira chuva do ano causou estragos no bairro. Prefeitura investe R\$340 milhões em obras. Rio de Janeiro: O globo, 2013. Disponível em <http://oglobo.globo.com/rio/bairros/enchentes-emjacarepágua-ate-quando-7241245>. Acesso em 29 de dez. de 2014.

CARVALHO, R. P. B. Ocupação dos solos em terrenos marginais às lagoas costeiras: mudanças e perspectivas ambientais frente a expansão urbana - O caso da lagoa de Jacarepaguá (Rio de Janeiro). 2013. 155f. Dissertação (Mestrado em Geografia) - Programa de Pós-Graduação em Geografia, Universidade do Estado do Rio de Janeiro. Rio de Janeiro, 2013.

CARVALHO, R. P. C. Geoindicadores físico-ambientais aplicados na avaliação da conectividade de bacias hidrográficas e seus efeitos em sistemas urbanos: O exemplo das bacias do Rio Grande e do Rio Anil (município do Rio de Janeiro). 2017. 272f. Tese (Doutorado), Universidade do Estado do Rio de Janeiro, Instituto de Geografia. Rio de Janeiro, 2017.

CARVALHO, L. M. V. de; JONES, C. Zona de convergência do atlântico sul. In: CAVALCANTI, I. F. A. (Org.). Tempo de clima no Brasil. São Paulo: Oficina de textos, 2009. p. 95-125.

CARVALHO, L. M.; JONES, C.; LIEBMANN, B. Extreme precipitation events in southeastern south america and large-scale convective patterns in the south atlantic convergence zone. Journal of Climate, v. 15, n. 17, p. 23772394, 2002.

COSTA, N. M. C. Análise Ambiental do Parque Estadual da Pedra Branca, por Geoprocessamento: Uma contribuição ao seu Plano de Manejo. Tese de Doutorado - Programa de Pós-graduação em Geografia (PPGG), Universidade Federal do Rio de Janeiro, Rio de Janeiro. 2002. $317 \mathrm{p}$.

COSTA, V. C. Proposta de Manejo e Planejamento Ambiental de Trilhas Ecoturísticas: Um Estudo no Maciço da Pedra Branca Município do Rio de Janeiro (RJ). 2006. 325 f. Tese (Doutorado) - Instituto de Geociências, Universidade Federal do Rio de Janeiro, Rio de Janeiro, 2006.

FERREIRA, F. P. M.; CUNHA, S. B. Enchentes no Rio de Janeiro: Efeitos da Urbanização no Rio Grande (Arroio Fundo) - Jacarepaguá. Anuário do Instituto de Geociências/UFRJ, Rio de Janeiro, v. 19, p. 79-92, 1996.

FERREIRA, N. J.; SANCHES, M.; SILVA DIAS, M. A. F. Composição da Zona de Convergência do Atlântico Sul em períodos de El Niño e La Niña. In: Revista Brasileira de Meteorologia, v.19, n.1, p. 89-98, 2004.

FREITAS, M. M. de; VARGAS, M.; CASTANHEIRA, S.; FINGERL, F. R. A influência dos remanescentes agro-pastoris do Maciço da Pedra Branca na dinâmica hidrológica das encostas. In: OLIVEIRA, R. R. (Org.) As marcas do homem na floresta: história ambiental de um trecho urbano de Mata Altantica. Rio de Janeiro: Ed. PUC-RIO, 2005. Cap. 4, p.143-164.

FRYIRS, K. A. (Dis)Connectivity in catchment sediment cascades: aa fresh look at the sediment delivery problem. Earth Surface Processes and Landforms. North Ryde, v. 38, p. 30-46, 2013.

FUNDAÇÃO GEO-RIO. Os 50 maiores acidentes geológicos-geotécnicos na cidade do Rio de Janeiro entre 1966 a 2016. Rio de Janeiro: Prefeitura, 2016, 113 p. Disponível em < http://alertario.rio.rj.gov.br/>. Acesso em 05 jan. 2017.

FUNDAÇÃO GEO-RIO. Relatório Anual de Chuvas 2005. Rio de Janeiro: Prefeitura, 2005. Disponível em < http://alertario.rio.rj.gov.br/>. Acesso em $18 \mathrm{dez} .2014$.

FUNDAÇÃO GEO-RIO. Relatório Anual de Chuvas 2006. Rio de Janeiro: Prefeitura, 2006. Disponível em < http://alertario.rio.rj.gov.br/>. Acesso em $18 \mathrm{dez} .2014$.

FUNDAÇÃO GEO-RIO. Relatório Anual de Chuvas 2008. Rio de Janeiro: Prefeitura, 2008. Disponível em < http://alertario.rio.rj.gov.br/>. Acesso em 18 dez. 2014.

FUNDAÇÃO GEO-RIO. Relatório Anual de Chuvas 2009. Rio de Janeiro: Prefeitura, 2009. Disponível em < http://alertario.rio.rj.gov.br/>. Acesso em 18 dez. 2014. 
FUNDAÇÃO GEO-RIO. Relatório Anual de Chuvas 2011. Rio de Janeiro: Prefeitura, 2011. Disponível em < http://alertario.rio.rj.gov.br/>. Acesso em 18 dez. 2014.

FUNDAÇÃO GEO-RIO. Relatório Anual de Chuvas 2012. Rio de Janeiro: Prefeitura, 2012. Disponível em < http://alertario.rio.rj.gov.br/>. Acesso em 18 dez. 2014.

FUNDAÇÃO GEO-RIO. Relatório de Correlação entre Chuvas e Escorregamentos para a Cidade do Rio de Janeiro no ano de 2011 . Rio de Janeiro: Prefeitura, 2011a. Disponível em < http://alertario.rio.rj.gov.br/>. Acesso em 05 jan. 2017.

FUNDAÇÃO GEO-RIO. Relatório de Correlação entre Chuvas e Escorregamentos para a Cidade do Rio de Janeiro no ano de 2012. Rio de Janeiro: Prefeitura, 2012a. Disponível em < http://alertario.rio.rj.gov.br/>. Acesso em 05 jan. 2017.

FUNDAÇÃO GEO-RIO. Volume mobilizado das ocorrências (totais) por bairro para o município do Rio de Janeiro no período 20102013. Rio de Janeiro: Prefeitura, 2013. Disponível em < http://alertario.rio.rj.gov.br/>. Acesso em 18 dez. 2014.

GONÇALVES, A. L. Barra da Tijuca, o lugar. Rio de Janeiro: Thex, 1999. p.167.

HARVEY, A. M, A. M. Effective timescales of coupling within fluvial systems. Geomorphology, v. 44, p. 175-201, 2002.

ISTOÉ. Maior chuva dos últimos 44 anos já matou 103 no RJ. Rio de Janeiro: ISTOÉ Independente. Reportagem do dia 06/04/2010. Disponível em

http://www.istoe.com.br/reportagens/63010_MAIOR+CHUVA+DOS+ULTIMOS+44+ANOS+JA+MATOU+103+NO+RJ?pathImagens=\&p ath=\&actualArea=internalPage $>$. Acesso em 29 de dez. de 2014.

JATOBÁ, L.; LINS, R. C. Tópicos Especiais de Geografia Física. Recife: UFPE, 2001. 103p.

JORNAL NACIONAL GLOBO. Trecho de reportagem do dia 14/02/1996. Disponível em: https://www.youtube.com/watch?v=Ew6XZHbNDIg.

MARQUES, J. S. A Participação dos Rios no Processo de Sedimentação da Baixada de Jacarepaguá. 1990. 437 f. Tese (Doutorado em Geografia) - Instituto de Geociências e Ciências Exatas, Universidade Paulista Júlio de Mesquita Filho - UNESP, Rio Claro, 1990.

RIBEIRO, M. F. Análise ambiental aplicada à definição da zona de amortecimento no Parque Estadual da Pedra Branca (Município do Rio de Janeiro, RJ), com base em geoprocessamento. Tese (Doutorado), COPPE/UFRJ, 2013. 407 f.

RIBEIRO, M. F.; COSTA, V. C. da; NETO, M. N.; FREITAS, M. A. V. An Analysis of monthly Rainfall and Its Relationship to the Occurence of Mass Movement and Flooding in Pedra Branca Massif in the City of Rio de Janeiro. Geographical Research. 2013. Disponivel em < http://www.ivig.coppe.ufrj.br/noticias/Documents/An\%20Analysis\%20of\%20Monthly\%20Rainfall.pdf>. Acesso em 05 out. 2014.

SILVA, A. M.; SCHULZ, H. E.; CAMARGO, P. B. Erosão e hidrossedimentologia em bacias hidrográficas. São Paulo: Ed. Rima, 2003. 140 p.

THOMAS, M. F. Landscape sensitivity in time and space. Catena, 42, 83-99, 2000.

TUCCI, C. E. M. Drenagem urbana. Ciência e Cultura, v. 55, n. 4, São Paulo, p. 10-11, 2003.

VALLEJO, L. R. CAMPOS, R. de M.; SANTOS JÚNIOR, W. M. Parque Estadual da Pedra Branca (RJ): caracterização, gestão e conflitos territoriais. In: Congresso Brasileiro de Unidades de conservação, 6, 2009, Curitiba. Anais... Curitiba: Fundação O Boticário de Proteção à Natureza, 2009. 